\title{
Integration of human and social capital: the experience of Russian, Chinese and European corporations
}

\author{
Pavel Deriugin ${ }^{1,2^{*}}$, Olga Yarmak $^{2}$, Ekaterina Strashko ${ }^{2}$, Elena Kamyshina ${ }^{3}$, and Olesya Bannova $^{3}$ \\ ${ }^{1}$ St. Petersburg State University, St. Petersburg, Russian Federation \\ ${ }^{2}$ Sevastopol State University, Sevastopol, Russia \\ ${ }^{3}$ St. Petersburg State Electrotechnical University, St. Petersburg, Russian Federation
}

\begin{abstract}
The article presents the results of an empirical study of the conversion of two forms of capital human and social in the conditions of private corporations in Russia, China, Spain. In theoretical studies, conversion is shown as a key synergistic moment in the creation of profits and rent. Based on a multiparadigm methodological approach, a methodology has been constructed that allows one to assess the degree of conversion of human and social capital in the value dimension. An analysis of the value networks of employees of corporations in Russia, China, Spain made it possible to draw general conclusions regarding sociodynamics and options for converting human and social capital: unity/harmony of capital; differentiation/disharmony of capital; different ratios of unity/differentiation of capital. Empirical material shows a significant difference in the characteristics of the conversion of human and social capital of Russians, Chinese and Spaniards according to the following criteria: the density of connections in the respondents' value networks; in the weight characteristics of indicators; in a specific manifestation of generalizing criteria - prosperity and team spirit. The proposed strategy for diagnosing capital conversion is of an applied nature and is used in several other studies.
\end{abstract}

\section{Introduction}

\subsection{Relevance}

Sociological analysis of the issues of integration of human and social capital is relevant both scientifically and applied. From a theoretical point of view, the conversion itself, i.e., integration and mutual transitions of some forms of capital into others, is considered as a condition for the emergence of a synergistic effect, which is expressed in the emergence and increase of profits and rent [1]. Such turnover of capital was considered by Marx to be the basis of reproduction [2]. As V. V. Radaev notes, capital conversion should be understood as a mechanism for increasing value: capital, in fact, is understood as an accumulated economic resource, which is included in the processes of reproduction and value increase by mutual conversion of its various forms [3]. The social aspect of the problem is important. The overwhelming majority of the workingage population of Russians, Chinese, and Europeans work in corporations. This is the most massive part of the population and the active part of the societies under consideration [4].

\subsection{Problem}

Corporations are privately owned. For Russia and China, the experience of their activities is historically negligible in contrast to European corporations. The problems of Russian corporations are, among other things, that most corporations are destroyed in the first 1-2 years of existence; there is a gap in the potential of human and social capital, which affects the negative attitude towards private corporations; the specifics of state regulation and national mentality that affect the harmony of capital have not been studied. Consideration of the integral approach to the study of the conversion of human and social capital is relevant [5].

Corporations are such a social institution where human and social capital are intertwined in the most essential way. Such interweaving constitutes a synergistic effect, revealing the systemic nature and systemic connections of various forms of capital. In this regard, it is important to turn to research on the values of corporate employees as a sociological research object, in which the potentials of human and social capital find their real embodiment and realization. The established values determine and transmit social institutions and social relations (T. Parsons), ensure adaptation and socialization of the individual and contribute to the maintenance of social order not only in corporations themselves, but also in society. In the conditions of modern Russia, corporate values are of particular importance for designing the effective institutional development of many other institutions interacting with corporations. It is the values that act as a kind of

Corresponding author: ppd333@rambler.ru 
reference point for the emerging capitals and have a decisive influence on the formation of the values of most Russians. The human and social capital of any corporation is in the process of continuous changes social dynamics, since the corporation itself is in continuous movement, a qualitative evolutionary change. Therefore, the theoretical, methodological, and empirical study of this sociodynamics is of considerable scientific interest. Along with this, we can talk about the presence of various unresolved issues and problems in the theoretical and scientific coverage of the harmony and ratio of human and social capital within corporate structures.

A special practical problem is the transition to a value-based approach to management. In modern conditions, corporations make decisions, each of which has a value aspect that, to a greater or lesser extent, orientates companies to make decisions that meet the goals of business strategies and community problems. Along with this, numerous data indicate that the practical component of empirical methods and tools is poorly focused on the study and analysis of indicators of value analysis.

\section{Methods}

\subsection{Methodology}

The development of a methodology for studying the relationship of human and social capital in the corporations' system of employee's corporate values was carried out in the framework, studying the ideas of sociologists about human and social capital, as well as about the society values and the features corporate values.

The essence of human and social capital is seen as changing with the formation and development of modern society. So, at the pre-industrial stage (before the 18th century), human capital was identified with knowledge aimed at achieving results, which was possessed only by a narrow circle of people who received it as «sacred knowledge» mainly in universities.

The first attempts to provide a scientific basis for human capital during this period are associated with the ideas of the economist W. Petty, outlined in the book «Political Arithmetic». According to K. Marx, W. Petty was the first to conclude the population as the wealth of any nation. Further, in Europe of the 19th century - the first half of the 20th century, the development of ideas about human capital is associated with the knowledge that can be implemented in practical business (A. Smith and D. Ricardo). A significant contribution to the development of the theory of the question at this time was made by the works of K. Marx, A. Marshall, JB Clark, V. Pareto. During this period, mass vocational education appeared, numerous technological and technical institutes and colleges were opened, the main goal was to provide mass production with new knowledge. Human capital, which contributes to the practical organization of business and is considered a condition of competitiveness, is beginning to be understood as dependent on intrapersonal characteristics - motivation, interests, values (school of human relations - E. Mayo, A. Maslow, D. McGregor, etc.). Later, in the late industrial stage, defined as neoclassical, starting in the 1960s in Europe, the USA, Japan, there is a «world outlook shift» in the awareness of the importance of the role of the qualities of a businessperson, primarily in the works of T. Schultz, G. Becker, J. Mintzer representatives of the Chicago School.

The central ideas of T. Schultz were the provisions on an expanded understanding of the role of investment in not only university education, but also concern for the health and well-being of the company's employees. From the point of view of G. Becker, knowledge, ability, and skills to «do business» should be considered not only as a «reserve», but also as a «source» of firm income, the need to form motivation and accumulate knowledge, work experience, starting from the period of growing up. In the works of $\mathrm{J}$. Mintser, a conceptual position regarding vocational training, which later becomes the main factor in the distribution of income, is formulated. In his work «Schooling, Experience and Earnings» (1974) J. Mintser described the concept of the overtaking period. The main idea of the concept lies in the prospects of choosing professions that are focused on the future.

A significant contribution to the development of the theory of human capital during this period was made by the work of other foreign researchers. Among them: L. Thurow, who showed the intellectual basis of human capital and the fundamental role of integrating the skilled workforce of organizations that determine the «future of capitalism». E. Fromm revealed the humanistic content of efficiency on the basis of psychoanalytic principles. G. Psakharopoulos showed a set of positive consequences that accompany investments in human capital. J. Ben-Porat formed the concept of cultivating human capital throughout life (the so-called Ben-Porat model). M. Bowen revealed the decisive role of the «family field» in the formation of human business qualities. J. Kendrick showed the capabilities of the costly method of human capital analysis. B. Chiswick revealed the influence of a person's position in the labor market depending on the accumulated business competencies, and others.

An interesting fact is the attitude to the problem in Russia. Research by V. I. Peftiev and N. V. Dutov provide evidence that in Russia the concept of «human capital» was discussed long before the corresponding discoveries of Western scientists. However, as subsequent studies of the history of the formation of scientific data on human capital in Russia show, these ideas did not find their proper development.

1980 s to 2000 s a new understanding of human capital was formed, and it is associated with the changed structure of the intangible factors of the economy and the increasing role of information. New requirements of the time are directly dependent on the quality of human capital - the emergence of information capital. Since 2000 the basis of human capital is recognized as noncognitive and emotional skills formed in the first years of a person's life. Conclusions are formulated about the 
basic role of the family, the preschool period of a person's life, school, and university education.

In the current modern Russian situation, the following are noted as topical areas of research on human capital and ability to «do business». Increasing the role of human efforts in the formation of the intellectual component of efficiency is in the face of growing inequality. There is also increasing the role of digital competencies; the growing importance of sociocultural assets of modern Russia in shaping the business activity of Russians; the relevance of an in-depth analysis of negative causes and trends in the development of imbalances in human capital. There is enhancing interdisciplinary approaches to understanding business behavior; integration of macro-, meso- and micro-levels of research; bridging the gap between the development of the spiritual and business components of human capital; problems of family influence on the business qualities of the younger generation of the Russian elite, entrepreneurs, engineers, etc.

Another part of the research methodological framework focuses on the analysis of values. Theoretical and empirical studies of corporate values have been characteristic of sociological science since its inception, and the attention of sociologists to values has invariably been associated with the study of the specifics and characteristics of values within corporate organizations. Direct attention to corporate values in the 50-60s was paid by T. Parsons, who showed the characteristics of corporations as social organizations, in which the main elements of its structural and functional paradigm are implemented.

Further, we should refer to the work and research results of M. Rokich, who at the turn of the 60-70s conducted large-scale field research on a nationwide American sample and showed that people working in corporate structures are characterized by special values that are different from the values of government officials, housewives, and people who are selfemployed. The basis of the methodology of this study is formed on a set of theoretical positions, the basic provisions of which were the provisions of M. Weber's interpretive of sociology, which allows us to consider the integration of human and social capital from the point of view of transformations of the internal structures of the individual.

The research methodology is formed on a set of theoretical positions, the basis of which was the interpretive sociology of M. Weber, which allows us to consider the integration of human and social capital from the point of view of transformations of the internal structures of the individual. The positions of P. Sorokin's culturological approach in the ideas of capital integration among actors of different social statuses are used. The positions of G. Simmel, M. Rokich, N.I. Lapin, V.A. Yadov, allowing considering the processes of integration of various forms of capital from the standpoint of the value approach.

The main provisions of the research methodology defined in many publications [6], [7]. In our study, the business qualities of a person are considered as indicators of human capital, i.e., qualities that ensure production and profit creation. Other qualities that are analysed in the study are communicative, collectivist qualities and the qualities of a good person - universal human qualities. Analysing the degree of importance and significance of certain qualities of human and social capital is from the point of view of the respondents. The construction of networks of these values allowed comparing, analysing, and weighing the networks of respondents' values and identifying what unites and what is problematic and peculiar in the system of values of human and social capital among Russian, Chinese, and European employees of corporations - to assess the degree of integration-conversion of capital.

In our opinion, for the interests of the network approach in the study of corporate values, the most productive one can be considered a theoretical framework based on the study of the dialectical relationship of object and spiritual values. They have found their reflection in the minds of people (in their value orientations, attitudes, and beliefs) and supplemented by the principles of interpretive sociology. Where do we see the advantages of this approach? There are several of them. First, in this case, it becomes possible to present corporate values comprehensively: as a material and spiritual phenomenon, as a good and an ideal at the same time, as a social norm and personality attitudes. Second, corporate values can be interpreted as value judgments of the corporation staff, expressing their subjective experience and rational understanding of the objective situation. Third, the value presented in this light can reveal its «significance» for making a choice from a set of alternatives.

It should also be noted that the designated positions on the essence of values reveal one of the methodological foundations of the study of corporate values in various scientific disciplines, i.e., as a basic scientific setting (economics, psychology, axiology, history, etc.), which were borrowed by sociologists in the interests of conducting sociological research. Corporate values as a supra-individual entity are not reducible to the sum of the values of its participants, although they are interconnected with the individual values of its employees.

From the point of view of sociology, corporate values cannot be attributed to any one member of a corporation, although these values are realized through the actions and actions of specific people. The idea of the supraindividual nature of the corporation is identical to the approach of N. Luhmann in the understanding of society. Corporations are akin to society in the sense of striving to distinguish themselves, isolate themselves from the outside and identify, unite within. Corporations constitute themselves by differences in relation to other social institutions, distinguishing themselves and dissociating themselves from other corporations. These differences are formed on the characteristics of the human capital of corporate employees. For sociological science, this has long been an axiom that is not a controversial fact. The nature of corporate values is social and group, since these values, as phenomena of a mass order, arise because of social interaction regarding the receipt of profits - based on human capital. But since 
their carriers are people who occupy a corresponding position in the corporate hierarchy, it follows that there are two directions of development and research of the sociodynamics process along the axes of coordinates: the corporation is the personality of the employee, the corporation is the society. Corporate values are dependent on the values of its employees, but at the same time they have relative independence, they are irreducible to these values and sometimes opposed to the values of the employees of the corporation. Thus, the relationship between human and social capital within corporations can develop in many ways.

The object of empirical research is employees of private corporations in the Russian Federation, China, and Spain. The sample consisted of 634 people, approximately equally from each country. The result is summarized in the form of tables and network diagrams based on the Ucinet software. Data visualization was prepared using Netdraw, as well because of the development of a special program created by students of the St. Petersburg State Electrotechnical University (team leader - K. D. Danilov). The limitations of the study are in a small sample, as well as in some difficulties and inconsistencies in translations, which reduces the reliability of the data obtained.

\subsection{Hypothesis}

External environment - national culture, traditions and values of society predetermine the nature of the integration of human and social capital of employees. The integration of capital is influenced by the leaps and speed of social change, when solving pragmatic problems, the possibilities of human capital, due to the differences in social time and space, which are characteristic of different cultures, are practically not considered. In the West, as you know, «time is money», in the East, «time is the master» [5]. Based on the analysis of a preliminary study of the trans-regional characteristics of human and social capital, it is assumed that among the employees of Chinese corporations, the consistency and harmony - conversion - of human and social capital will be significant. In European corporations, the conversion of human and social capital will be more differentiated. In Russian corporations, the uncertainty and inconsistency of capital conversion will be recorded.

\section{Results and discussion}

\subsection{Result 1}

The density of relationships between indicators of human and social capital turned out to be different. The highest density was recorded in the networks of employees of Chinese corporations (Table 1).
Table 1. Indicators of the density of network connections between capital indicators.

\begin{tabular}{|c|c|c|c|c|}
\hline & \multicolumn{2}{|c|}{$\begin{array}{c}\text { Positive network } \\
\text { connections }\end{array}$} & \multicolumn{2}{|c|}{$\begin{array}{l}\text { Negative network } \\
\text { connections }\end{array}$} \\
\hline & Strong & Weak & Strong & Weak \\
\hline \multirow{2}{*}{ Russia } & 2 & 13 & 2 & 11 \\
\hline & \multicolumn{2}{|c|}{ Total: 15} & \multicolumn{2}{|c|}{ Total: 13} \\
\hline \multirow{2}{*}{ Spain } & 2 & 13 & 4 & 18 \\
\hline & \multicolumn{2}{|c|}{ Total: 15} & \multicolumn{2}{|c|}{ Total: 22} \\
\hline \multirow{2}{*}{ China } & 17 & 15 & 0 & 0 \\
\hline & \multicolumn{2}{|c|}{ Total: 32} & \multicolumn{2}{|c|}{ Total: 0} \\
\hline
\end{tabular}

The number of positive ties between the networks of employees of Russian and Spanish corporations coincided: 2 strong positive ties and 13 weak positive ties each. As for negative connections, they differed in their quantitative characteristics. Russians had only 14 such connections ( 2 - strong negative and 12 - weak negative). Spanish corporate employees have only 22 (4 - strong negative and 18 - weak), i.e., among employees of Spanish corporations, a more significant differentiation of capital is recorded. As for the employees of Russian corporations, the indicators of capital integration were like the results of employees of Spanish corporations.

\subsection{Result 2}

Employees of the analysed corporations estimate the weight characteristics of the qualities of social and human capital in different ways. As the equal qualities of human and social capital are recorded among the employees of Chinese corporations.

Employees of Chinese corporations give approximately the same assessment of both the business and collectivist qualities of other people (respectively, business - 3.98 and collectivist - 3.95). At the same time, they put down the most critical (low) ratings of other people, in comparison with the ratings of employees of Russian and Spanish corporations. This indicates a rather demanding and critical attitude of the Chinese towards the qualities of the people around them. Among the business qualities, the most important places are taken by purposefulness and prosperity, the least assessed are power and prudence. Respectful attitude to people and team spirit were in the first place among social qualities, in the last - altruism and caring. Employees of Russian corporations appreciate the importance of the social qualities of their colleagues, preferring them to business qualities. In the first places among the social qualities, they showed the quality of mutual assistance and benevolence, in the last of altruism and team spirit. 
Among the business qualities in the first place among the Russians were prudence and prosperity, in the last leadership and imperiousness. Employees of Spanish corporations appreciate the importance of the qualities of social capital - collectivist qualities. They put benevolence and respect for people in the first place. At the bottom of the list of socially relevant qualities are team spirit and altruism, which are alike the results of the Russians. Among the business qualities, the Spaniards singled out as the most important leadership and pragmatism, in the last places - prudence and imperiousness.

Thus, the weighting characteristics of qualities record the diversity of respondents' ideas about the importance of qualities-values. We emphasized once again the peculiarity of the results of the Chinese respondents, whose weight characteristics of the business and collectivist qualities are practically at the same level of assessment, i.e., as equal.

\subsection{Result 3}

The indicator of human capital "prosperity" as one of the central characteristics of successful business selfrealization of an individual is differently integrated into networks of connections with other indicators of human and social capital in the corporations under consideration.

According to several studies, success and prosperity should be considered as dependent on the conditions and social situation: success as a sociocultural category is possible only in line with certain social orientations of the characteristics set by society, i.e., is not only a sociopsychological category, but also socially conditioned [8]. In modern studies, prosperity and success in market conditions is considered as a value characterized by two parameters: the focus and effectiveness of the implementation of human capital [9].

For Russians, business success is characterized by a strong negative and even conflicting connection with two important social qualities - mutual assistance and goodwill towards other people. In other words, Russian corporate employees believe that a successful person is more likely to be incapable of sincere help, as well as showing goodwill towards them. Successful people think only of themselves and are not ready to help other people in difficult times; they are credited with narcissism, psychopathy, and Machiavellianism [10], [8].

An even higher quality of prosperity is differentiated among employees of Spanish corporations. For Spaniards, prosperity conflicts (the same strong negative correlation as for Russians) with three social characteristics - benevolence, respect, and concern for other people. Research by E.O. Kuzmenko showed that, firstly, from the point of view of the values of mass culture, European "success" is a paradoxical reduction of the diversity and complexity of the value-semantic and socio-psychological attitudes of the individual to a certain simplified standardized value [8]. Secondly, success as a phenomenon is associated with the intensification of all aspects of social life, acts as a translator of role behavior, functionally in demand by society, demonstrates a new level of standardization of cultural samples and reflects value transformations characteristic of modern society and modern culture [8]. As a summary of the European understanding of prosperity: «there is a shift in the «fulcrum» of personality development from internal foundations to external ones, the energy of individual resources is released outside, and the adaptation scheme is «overturned». Social self-affirmation becomes a decisive factor in the formation of a person. Changing depending on different historical contexts, these tendencies preserve the principles of the functioning of Protestant ethics» [11].

Among employees of Chinese corporations, in terms of weight parameters, prosperity is second only to dedication. At the same time, the quality of prosperity is associated with a significant network connection with all the other 11 indicators-qualities, i.e., in fact, it is a systemic quality. Let us emphasize that a strong positive relationship of prosperity with all other qualities was noted in 9 cases out of 11 . The obtained result suggests that employees of Chinese corporations understand and appreciate prosperity because of hard work, constant attention to their affairs, which ensure the common good. In general, this situation fully reflects the mentality and socio-economic development trends of China. It is well known that having realized the «Chinese dream» of a «low-income society», the modern guidelines of Chinese society are aimed at building a «prosperous society» aimed, according to the General Secretary of the Central Committee of the Communist Party of China Xi Jinping, at turning China into a rich and strong state. And this «Chinese dream from beginning to end (completely) is the dream of the Chinese people, the dream of every Chinese» [12].

\subsection{Result 4}

The inclusion of the "team spirit" indicator in the network of connections with other indicators of human and social capital reveals the specifics of social integration in corporations. Statistical data on the place of the team spirit indicator shows that this indicator is included in the network connections of the social capital subsystem in the most significant way - 11 strong positive connections. At the same time, the integration of this indicator among the Spanish and Chinese respondents reaches its maximum - 5 links each. This inherently integrating indicator in the system of social values of employees of Chinese corporations is included in the human capital subsystem along with some business qualities and characteristics. Recall that among employees of Chinese corporations, the indicator of team spirit is at a high level in the rating of collectivist qualities - second in weight. In contrast to the perceptions of employees of Russian corporations, for whom this indicator closes the rating of collectivist qualities (6th place) and is minimally included by strong ties both in the subsystem of social capital and in the 
subsystem of human capital, there are only two strong network ties (a kind of «complex Emeli» [13].

\section{Conclusions}

First of all, we noted the confirmation of the results of theoretical studies on the options for converting human and social capital: harmony and unity - the equivalence of these capitals; differentiation-opposition of capital; different ratio of capital connections.

In the social sense, corporations are associations that participate in market relations in a free market; it is freemarket relations that serve as the source of such corporate values, where numerous relationships arise between human and social capital. Further, these are such associations, participation in which inevitably transforms the worldview of its participants, their values: for the formation of corporations, where there is a shift in the moral and ethical foundations of society, reflecting the social attitude towards human capital. In social terms, it is important that corporations form a special solidarity, cohesion, based on the recognition of the important role of human capital, without which their survival becomes impossible. The values of corporations are characterized by a struggle for high production results, a competitive struggle for survival, and a desire to monopolize markets, at least control over a certain market sector. These are social groups with supraindividual social properties, formed on unshakable corporate principles: priority by the group of goals and group values over all other goals and values of its participants; the determining influence of official business relations on all other informal relations (previously - masters, apprentices, now - founders, management, other employees and representatives of the environment from the external environment); the practice of collegial development of strategic management decisions. In social terms, Russian corporations act as one of the forms of social associations in a free market, based on the rights to preserve private property and legality, guaranteed by the Constitution of the Russian Federation.

Under the conditions of the national culture of China, the conversion of human and social capital turned out to be the most significant, significantly higher than under the conditions of Russian and European corporations. The characteristics of human and social capital among employees of Chinese corporations are perceived as interconnected and interdependent, - inseparable, - as an integral, unified system. The prospect of such integration for the development and formation of the human capital of employees of Chinese corporations lies in the support of their business activity by the social environment, and the ability to achieve economic results is approved and strengthened by public opinion. In such social ties, the values of economic development and the goals of corporate organizations are to a large extent an indicator and measure of all «humanity» and the weight of an individual. First, the Chinese national culture "absorbed" the corporate form of organizing labour activity and subordinated, rebuilt, oriented its development based on its national interests and values - based on Chinese specifics. Further research (interviews with heads of private Chinese corporate organizations in small business) showed the presence of many features of corporate culture, showing the consideration of the human capital of employees in conjunction with their social characteristics when hiring people, when determining measures of discipline, incentives, etc. Second, employees of Chinese corporations find themselves integrated into the system of both economic potentials (human capital) and into the system of social relations (social capital) as a single harmonious socioeconomic environment, which constitutes the most effective conditions for socialization and personal development.

Under the conditions of the national culture of European countries, human and social capital turns out to be more differentiated, divided: doing a job is one thing, building relationships is another [14]. The realities of Russian private corporations are in a difficult period of formation of interdependencies between human and social capital. The study of these trends presupposes large-scale research based on a network approach, which will make it possible to make an adequate diagnosis and identify trends in the formation of relationships between human and social capital as a condition for the socially oriented development of corporations.

\section{Acknowledgements}

The study was supported by the RFBR (Russian Foundation for Basic Research) in the framework of the scientific project No. 19-29-07443/19 "Scientific and educational centers as a factor in the formation of human capital in Russia: the format for creating world-class scientific and educational centers according to the Presidential Decree "On National Goals and Strategic Tasks of the Development of the Russian Federation for the period until 2024).

\section{References}

1. L.V. Zgonnik, Ter. Econ. 4, 105 (2007)

2. V.G. Shelepov, Ter. Econ. 3, 137 (2010)

3. V.V. Radaev, Econ. Soc. 4, 20 (2002)

4. Yu.V. Latov, N.E. Tikhonova, Ter. Econ. 2, 6 (2021)

5. S.A. Kravchenko, MGIMO Rev. of Int. Rel. 6, 15 (2010)

6. P.P. Deriugin, L.A. Lebedintseva, O.V. Yarmak, R.A. Travin, Res. Res. Soc. and Man. 4, 10 (2020)

7. P.P. Deriugin, Theoretical and methodological analysis of social diagnostics of interpersonal relations, 43 (2001)

8. E.O. Kuzmenko, Izv. Ur. Fed. Un. J. 23, 178 (2017)

9. V.V. Zhokhova, D.A. Sokolova, Ves. P. S. Un. E. 85, 44 (2018)

10. From a scientific point of view: 3 negative qualities of all successful people, Fem. (2019) 
https://femmie.ru/ya-ne-stareyu-a-stanovlyusmudrej-155587/ Date of the application: 12.09.2021

11. O.V. Mikhailova, Tom. St. Un. J. 307, 50 (2008)

12. S.Yu. Raspertova, Ves. of Mos. St. Lin. Un. H. 13, 724 (2015)

13. O.A. Efremov, MSU Ves. 3, 55 (2014)

14. P.V. Lemanova, Ter. Econ. 3, 28 (2009) 